\title{
Conhecimentos tradicionais em torno das plantas medicinais e currículo do ensino de ciências
}

\author{
Glaucia Sousa Moreno ${ }^{1}$, Gabriela da Silva ${ }^{2}$ \\ ${ }^{1}$ Universidade Federal do Sul e do Sudeste do Pará - UNIFESSPA. Faculdade de Educação do Campo/Instituto \\ de Ciências Humanas. Avenida Folha 31, Quadra 07 s/n. Marabá - PA. Brasil. glaucia@unifesspa.edu.br. \\ ${ }^{2}$ Universidade Federal do Sul e do Sudeste do Pará - UNIFESSPA
}

RESUMO. A evolução do conhecimento científico ao longo dos séculos, além dos aspectos tecnológicos e inovações, propiciou o que podemos chamar de "metamorfose cultural" em diversas áreas. Por meio de sua atuação e da ideologia predominante da "ciência como única e/ou principal fonte de verdade" nos deparamos com a perda ou estagnação de conhecimentos populares adquiridos em décadas, tais como o conhecimento tradicional sobre Plantas Medicinais, os quais vêm sendo substituídos pelo conhecimento farmacêutico que contraditoriamente também é produzido com base no conhecimento dos "especialistas tradicionais". Por meio de uma pesquisa in lócus na Agrovila Nova Conquista, no município de Açailândia, Estado do Maranhão, encontramos alta diversidade de plantas medicinais (42 espécies) encontradas nesta área, visto que detectamos seu uso com finalidades medicinais. A partir de entrevistas gravadas, conversas informais e da leitura de referencial teórico, construímos uma proposta pedagógica no ensino de ciências na escola de Educação Básica Oziel Alves em Açailândia-MA, que poderá contribuir para uma articulação entre elementos da realidade local e os conteúdos trabalhados no ensino de ciências na escola em questão.

Palavras-chave: Plantas Medicinais, Educação do Campo, Amazônia. 


\title{
Traditional knowledge of medicinal plants and science education curriculum
}

\begin{abstract}
Evolution of scientific knowledge over the centuries and technological aspects and innovations led to what we call "cultural metamorphosis" in several areas. Through its activities and the prevailing ideology of "science as the sole and/or main source of truth" we face the loss or stagnation of popular knowledge acquired in decades - such as traditional knowledge about medicinal plants - which is being replaced by pharmaceutical knowledge that is, in a contradictory way, also produced based on the knowledge of "traditional experts". Through research in locus in the Agrovila Nova Conquista, in Açailândia, Maranhão State, we found a high diversity of medicinal plants (42 species) found in this area and we identified their use with medicinal purpose. From recorded interviews, informal conversations and theoretical reading, we build a proposed pedagogical approach in science teaching in the Basic Education School Oziel Alves in Açailândia, Maranhão State, which may contribute to the articulation between elements of the local reality and the contents worked in science education at the school in question.
\end{abstract}

Keywords: Medicinal Plants, Rural Education, Amazon. 


\section{Conocimientos tradicionales sobre las plantas medicinales y el currículo de enseñanza de ciencias}

RESUMEN. La evolución del conocimiento científico a lo largo de los siglos, más allá de sus aspectos tecnológicos e innovaciones, propició lo que podemos llamar "metamorfosis cultural" en diversas áreas. Por medio de su actuación y de la ideología de la "ciencia como única y principal fuente de verdad" deparamos la pérdida o inmovilización de los conocimientos populares adquiridos en décadas, tales como el conocimiento tradicional sobre las Plantas Medicinales, los cuales vienen siendo sustituidos por el conocimiento farmacéutico que contradictoriamente también es producido en base al conocimiento de los "especialistas tradicionales". Por medio de una pesquisa in locus en la Agro villa Nueva Conquista, en el municipio de Açailândia, Estado de Maranhão, encontramos una alta diversidad de plantas medicinales (42 especies) en esta área y su uso con fine medicinales. A partir de entrevistas grabadas, conversaciones informales y de la lectura del referencial teórico, construimos una propuesta pedagógica para la enseñanza de ciencias en la escuela de Educación Básica Oziel Alves en Açailândia-MA, que podrá contribuir a una articulación entre elementos de la realidad local y los contenidos trabajados en la enseñanza de las ciencias en la escuela en cuestión.

Palabras clave: Plantas Medicinales, Educación Rural, Amazonia. 


\section{Introdução}

A partir da intensificação do processo evolutivo da ciência tem sido notável uma crescente apropriação das indústrias farmacêuticas no que tange ao conhecimento tradicional, como por exemplo, das plantas medicinais para a produção de fármacos produzidos a partir longas pesquisas científicas, situação que vem sendo cada vez mais frequente e por isso, relatada em diversos estudos como em Barbosa (2009), Camargo (2014) e Fernandes (2004). Concomitantemente, é crescente o número de comunidades tradicionais (tais como indígenas e camponeses) que tem se utilizado massivamente desses fármacos (DIEGUES, 2000). Essa relação ou inversão de valores é preocupante, no sentido da supervalorização de um saber em detrimento do outro, o que torna relevante um investimento no resgate aos conhecimentos construídos historicamente pelos povos e comunidades tradicionais, exercício que tentamos realizar com a construção dessa pesquisa.

$\mathrm{Na}$ perspectiva de relacionar $\mathrm{o}$ conhecimento tradicional sobre as plantas medicinais propriamente na Agrovila Nova Conquista no município de Açailândia, Estado do Maranhão, e o uso de medicamentos farmacêuticos pelos moradores da própria vila, realizamos a pesquisa in lócus, ressaltando esse processo de conhecimento por meio de entrevistas gravadas e/ou conversas informais com os "especialistas tradicionais" dessa comunidade. As entrevistas forneceram informações relevantes para as análises das espécies e uso cotidiano e propriedades medicinais das plantas utilizadas ao longo das gerações. Além disso, propomos uma reflexão sobre o papel da escola na permanência do conhecimento tradicional, por meio de práticas pedagógicas voltadas para o ensino das plantas medicinais na disciplina de Ciências para alunos do Ensino Fundamental da Escola Municipal Oziel Alves em Açailândia-MA.

A pesquisa e o desenvolvimento da presente proposta corresponderam às atividades didáticas pedagógicas de estágio de docência, obrigatório para os graduandos em Licenciatura em Educação do Campo da Universidade Federal do Sul e Sudeste do Pará (UNIFESSPA). O estágio constitui-se na vivência, observação e exercício profissional da docência no Ensino Fundamental e Ensino Médio na disciplina de Ciências e de Biologia, acompanhado por um professor do referido curso. A seguir, serão detalhadas mais informações sobre o curso de Licenciatura em Educação do Campo. 
Contexto em que o trabalho está inserido

O curso de Graduação em Educação do Campo da UNIFESSPA foi criado em 2009. Contudo, os primeiros cursos em Educação do Campo foram ofertados em 2007 na Universidade de Brasília (UNB), Universidade Federal de Minas Gerais (UFMG) e Universidade Federal da Bahia (UFBA). O referido curso tem por objetivo formar professores para atuarem nas escolas de Educação Básica, Ensino Fundamental e Ensino Médio nas Escolas do Campo (localizadas em áreas rurais do país).

Nesse curso o Ensino de Ciências e de Biologia, o último com intuito de contemplar o Ensino Médio, são entendidos como um elemento cultural e também de construção humana, considerando que os conhecimentos científicos e tecnológicos se desenvolvem em grande escala na sociedade atual. Isto atende a algumas demandas e preocupações conceituais e estruturais, que historicamente estiveram nas pautas de reivindicações dos movimentos sociais, como reconhecimento e valorização da diversidade dos povos do campo; formação diferenciada de professores; possibilidade de diferentes formas de organização do espaço escolar; adequação dos conteúdos às peculiaridades locais; o uso de práticas pedagógicas contextualizadas; difusão através da escola, do desenvolvimento sustentável e do acesso a bens econômicos, sociais e culturais. ${ }^{\mathrm{i}}$

Desta forma, pensar a Graduação em Educação do Campo significa atender a demanda de "inclusão social" das comunidades rurais no sudeste paraense, bem como a expectativa de que a diversidade sociocultural brasileira seja contemplada no processo educacional. Logo, pensar o ensino de Ciências e de Biologia na Licenciatura em Educação do Campo requer ter clareza do meio biofísico (ecossistema predominante) e dos fatores socioculturais inerentes nas comunidades rurais (reconhecendo a diversidade de fatores bióticos).

O viés dado no tratamento do ensino de Ciências apresenta relevância para a compreensão da vivência e atuação no mundo contemporâneo, privilegiando conteúdos, métodos e atividades que favoreçam um trabalho coletivo de educadores e educandos no espaço escolar e na sociedade, e que tenha a pesquisa como princípio educativo. Além disso, o ensino em Ciências da Natureza na licenciatura em Educação do Campo deve garantir a aproximação com a produção científica contemporânea, ao elencar temas de relevância social que tenham 
interligação com a produção histórica do lugar em que o sujeito vive.

Conhecendo a realidade do sujeito e o contexto sócio histórico em que ele vivencia, acreditamos que o educador formado neste curso seja capaz de elencar Temas Geradores ou Complexos Temáticos que representem o plano micro social ao qual o aluno esteja inserido. Enfim, este educador deverá estar preparado para ensinar as massas nas condições de ruptura com as antigas estruturas da sociabilidade do capital, contrapondo desta maneira a ideia amplamente tratada no ensino de Ciências, que faz uso de modelos e teorias para compreensão dos fenômenos naturais de forma pragmática, favorecendo um ensino que não envolva a sociedade e seu entorno.

\section{Objetivos}

O caminho pedagógico percorrido nesta pesquisa apresenta os seguintes objetivos:

- Descrever as espécies vegetais (plantas medicinais) utilizadas com a finalidade de tratamento de enfermidades na Agrovila Nova Conquista-MA;

- Refletir sobre o papel da escola na permanência do conhecimento tradicional, propondo práticas pedagógicas sobre as plantas medicinais no Ensino Fundamental da Escola Municipal Oziel Alves em Açailândia-MA;

- Desenvolver atividade prática em torno do ensino de Ciências utilizando como eixo temático "As Plantas Medicinais".

\section{Classificação etnobotânica das plantas medicinais encontradas na agrovila Nova Conquista-MA}

A primeira etapa no desenvolvimento deste trabalho se deu com uma pesquisa bibliográfica a respeito do tema para uma apropriação filosófica por parte do professor, pois conforme explica Freire (1996):

\begin{abstract}
Não há ensino sem pesquisa e pesquisa sem ensino. Esses fazeres se encontram um no corpo do outro. Enquanto o ensino contínuo buscando, reprocurando. Ensino porque busco, porque indaguei, porque indago e me indago. Pesquiso para constatar, constatando, intervenho, intervindo educo e me educo, pesquiso para conhecer o que ainda não conheço e comunicar ou anunciar novidade. (Freire, 1996, p. 29).
\end{abstract}

A partir do levantamento prévio do conhecimento dos alunos, foi possível confirmar a visão que estes possuem sobre a comunidade em que vivem, e por meio disto elaboramos o tema gerador do projeto, intitulado "O Cultivo de Plantas Medicinais no Assentamento Nova Conquista em Açailândia - MA”. 
Ainda no primeiro contato, encaminhamos os alunos a uma pesquisa com os seus pais e familiares, a respeito do uso dessas plantas (ver quadro a seguir). possível identificar as 42 espécies com fim medicinal utilizada pelos moradores da comunidade Nova Conquista.

Quadro 01. Nome popular, parte usada, forma de consumo e uso popular das plantas.

\begin{tabular}{|c|c|c|c|}
\hline NOME POPULAR & $\begin{array}{l}\text { PARTE } \\
\text { USADA }\end{array}$ & $\begin{array}{l}\text { FORMA DE } \\
\text { CONSUMO }\end{array}$ & USO POPULAR \\
\hline BABOSA & Folhas & Cataplasma & Cicatrizante, máscara capilar \\
\hline $\begin{array}{lr}\text { CAPIM } & \text { SANTO, } \\
\text { CAPIM LIMÃO ou } \\
\text { CAPIM DE CHEIRO }\end{array}$ & Folhas & Chá e banho de vapor & $\begin{array}{l}\text { Calmante, febre hipertensão arterial } \\
\text { (pressão alta) e caspa no couro } \\
\text { cabeludo. }\end{array}$ \\
\hline LIMOEIRO & $\begin{array}{l}\text { Casca, fruto, } \\
\text { folhas }\end{array}$ & $\begin{array}{l}\text { Chá, suco e banho de } \\
\text { vapor. }\end{array}$ & Gripe, depurativo do sangue \\
\hline NONI & Fruto & Suco & Anti-inflamatório \\
\hline ERVA CIDREIRA & Folhas e talos & Chá & $\begin{array}{l}\text { Calmante, hipertensão arterial (pressão } \\
\text { alta), febre, fígado. }\end{array}$ \\
\hline ALFAVACA & Folhas e talos & $\begin{array}{l}\text { Banho de } \\
\text { banho de vapor ersão, } \\
\text { inalação }\end{array}$ & Gripe, resfriado \\
\hline BOLDO ou SETE DOR & Folhas & Chá & Fígado, estômago, anti-inflamatório \\
\hline $\begin{array}{ll}\text { MASTRUZ } & \text { ou } \\
\text { MENTRUZ } & \\
\end{array}$ & Folhas & Sumo e cataplasma & $\begin{array}{l}\text { Anti-inflamatório, ataque de verme, } \\
\text { anemia, cicatrizante }\end{array}$ \\
\hline HORTELÃ & Folhas & Chá ou sumo & $\begin{array}{l}\text { Gripe, estômago (náuseas, digestão), } \\
\text { cólicas. }\end{array}$ \\
\hline ALGODÃO & $\begin{array}{l}\text { Azula } \\
\text { (semente), } \\
\text { folhas e talos }\end{array}$ & Sumo ou chá & Dor de ouvido, inflamação \\
\hline GENGIBRE & Raiz & Chá & Fungo na garganta, tosse, afrodisíaco. \\
\hline ROMÃ & Casca & Chá, suco (gargarejo) & $\begin{array}{l}\text { Garganta, anti-inflamatório, prevenção } \\
\text { de câncer }\end{array}$ \\
\hline AGRIÃO ou JAMBÚ & Folhas e flores & $\begin{array}{ll}\begin{array}{l}\text { Chá, } \\
\text { (lambedor) }\end{array} & \text { xarope } \\
\end{array}$ & $\begin{array}{l}\text { Gripe, analgésico, dor de dente, tosse } \\
\text { alérgica }\end{array}$ \\
\hline PINHÃO & $\begin{array}{l}\text { Folhas, noda } \\
\text { (leite), talo }\end{array}$ & Chá (fazer bochecho) & Dente, anti-inflamatório, boqueira \\
\hline PEPINO & Semente, fruto & Cataplasma, suco & $\begin{array}{llrl}\text { Hidratação e elasticidade da pele, } & \text { ela } \\
\text { hemorroida, pressão arterial } & & \\
\end{array}$ \\
\hline SENA & Folhas & Chá & Laxante, hemorroidas \\
\hline LARANJEIRA & Fruto, casca & Chá e suco & Gripe, laxante, estômago \\
\hline ARRUDA & Folhas & Sumo & Dor no ouvido \\
\hline MALVA DO REINO & Folhas e talos & $\begin{array}{lcl}\begin{array}{l}\text { Chá } \\
\text { (lambedor) }\end{array} & \text { xarope } \\
\end{array}$ & Gripe, tosse \\
\hline QUEBRA-PEDRA & Planta completa & Chá & Rins, fígado \\
\hline GERVÃO & Folhas & Sumo & Ferimentos, pancadas \\
\hline ALGODÃO & Folhas & Pó (folhas queimadas) & Cicatrizante, anti-inflamatório \\
\hline MAMÃO & $\begin{array}{l}\text { Folhas, semente } \\
\text { e fruto }\end{array}$ & Chá & Fígado, verme, regulador do intestino \\
\hline ALHO & Cabeça & Chá & Verme, prisão de ventre \\
\hline TOMARINDO & Folhas & Chá & Verme \\
\hline MANGA & Folhas & Chá & Febre \\
\hline CAJÚ & Casca & Chá & Disenteria, diarreia, \\
\hline
\end{tabular}




\begin{tabular}{|l|l|l|l|}
\hline GOIABA & Folhas e casca & Chá & Diarreia \\
\hline COCO & Água & Suco e cataplasma & Desidratação, anticaspa \\
\hline AZEITONA & Casca & Chá & Diarreia \\
\hline ABÓBORA & $\begin{array}{l}\text { Poupa } \\
\text { semente }\end{array}$ & $\begin{array}{l}\text { Dentro das refeições } \\
\text { (cozida), cataplasma }\end{array}$ & Regulador do intestino e verme \\
\hline TREVO & Folhas e talos & Cataplasma, chá & $\begin{array}{l}\text { Dor de ouvido, coração, sistema } \\
\text { nervoso }\end{array}$ \\
\hline MANGERICÃO & Folhas & Chá, banho & Dor de ouvido, banho de inalação \\
\hline QUIABO & Semente, fruto & Chá, cozido & Hepatite, intestino preso, diabete \\
\hline BANANA & Seiva, melado & Mangará & Gripe, infecção respiratória \\
\hline BETERRABA & Fruto & Sumo & Anemia \\
\hline VICK & Folhas & $\begin{array}{l}\text { Chá, } \\
\text { banho de vapor }\end{array}$ & Resfriado, nariz entupido, gripe \\
\hline ANADOR & Folhas & Chá & Dor de cabeça, febre, dores diversas \\
\hline JARDINEIRA & Folhas & Banho de vapor & Sinusite, resfriado, gripe \\
\hline JATOBÁ & Casca & Chá e sumo & Anemia, rins, \\
\hline MARACUJÁ & Fruto, casca & Suco & Pressão alta e calmante \\
\hline PIMENTA & Folha e fruto & Cataplasma & Furúnculo, gripe \\
\hline
\end{tabular}

Fonte: pesquisa de campo, 2015.

Com que frequência elas são utilizadas? Quais plantas medicinais são mais comuns na comunidade? Para que servem? Quais os efeitos colaterais? Com este roteiro preestabelecido, os educandos foram orientados a observarem as plantas e registrarem o momento com algumas fotografias em seus próprios aparelhos celulares.

Partindo para a sistematização da pesquisa realizada pelos alunos, buscamos fazer uma relação entre as informações colhidas por estes e a pesquisa que, enquanto professores, realizamos e levantamos um debate a respeito da importância dessa cultura e sua conjuntura histórica. Nisto, tentamos provocar a participação dos alunos conforme levantávamos alguns questionamentos, pois o fundamental é que os professores e alunos saibam que a postura entre ambos deve ser dialógica, aberta, curiosa, indagadora e não apassivada, enquanto fala ou enquanto ouve. (Freire, 1996, p. 86).

Essa abertura permitiu o contato direto com o eixo temático proposto: "plantas medicinais", o qual a partir dele, adentramos a interdisciplinaridade com outra área, principalmente em diálogo com ensino de química. 
Quadro 02. Eixo temático: Plantas Medicinais.

\begin{tabular}{|c|l|l|l|}
\hline EIXO TEMÁTICO & \multicolumn{1}{|c|}{ QUÍMICA } & \multicolumn{1}{c|}{ FÍSICA } & \multicolumn{1}{c|}{ BIOLOGIA } \\
\hline Plantas medicinais & $\begin{array}{l}\text { Reações; misturas } \\
\text { homogêneas e } \\
\text { heterogêneas; soluções }\end{array}$ & $\begin{array}{l}\text { (Chás) temperatura, } \\
\text { tempo de aquecimento. }\end{array}$ & $\begin{array}{l}\text { Estrutura da planta; } \\
\text { biodiversidade; tríade } \\
\text { solo- planta - atmosfera }\end{array}$ \\
\hline
\end{tabular}

Fonte: pesquisa de campo, 2015.

A partir do quadro acima, como já mencionado, apresentamos aos alunos um histórico das plantas medicinais no sentido mais geral, como se deu o seu descobrimento e qual a sua importância, tendo em vista que o tema é muito propício a se trabalhar com a interdisciplinaridade. Nesse mesmo debate discutimos a reação de um remédio feito com as plantas medicinais, utilizando termos químicos de misturas heterogêneas e homogêneas. Em visita a algumas moradias da comunidade, os alunos presenciaram o processo de preparação de um chá e, de maneira mais clara, foi possível identificar os tipos de reações e misturas, bem como a temperatura e o tempo ideal para seu preparo. Foi o primeiro momento em que se tornou perceptível a relação direta da química, onde discutimos as reações que são provocadas no organismo. Conversamos também sobre os compostos químicos encontrados na bula dos remédios e os educandos tiveram um possível primeiro contato com a temática. Além disso, discutimos questões pertinentes à diversidade de plantas medicinais existentes no mundo e as principais encontradas na agrovila.

Tendo em vista que a turma trabalhada era composta por alunos do Ensino Fundamental, com faixa etária entre 10 a 14 anos, não houve um aprofundamento direto em todos os conceitos e conteúdos propostos. No entanto, o professor do Ensino Médio pode se valer de todos esses conceitos para um ensino mais abrangente com os estudantes.

Nestas primeiras aulas utilizamos de diferentes recursos como: projetor multimídia, textos xerocopiados dentre outros. Em seguida, escolhemos as plantas que seriam utilizadas como: babosa, quebra pedra, capim santo, gengibre, mastruz, boldo, romã e hortelã. A escolha se deu devido estas serem as mais encontradas na comunidade.

Uma das estratégias que utilizamos, já pensando na confecção de um livro e no intuito de avaliar o aprendizado dos educandos, foi a produção de textos em diferentes gêneros. Sempre que realizávamos algum debate, quer seja sobre a importância ou mesmo a propriedade de alguma planta, partíamos para estas 
produções. Assim, os educandos puderam ficar à vontade para escrever da maneira que mais lhe agradava, alternando em sua escolha ao longo das aulas. Dessa forma, notamos um interesse maior para o trabalho de escrita de forma individual e em outros momentos por iniciativa de trabalho de escrita em grupos. Foram entregues trabalhos em forma de textos corridos, redações, cordéis, paródias, versos e até mesmo algumas histórias contando suas experiências. Como esta atividade se repetiu na maioria das aulas, fazíamos a leitura das produções individualmente e na aula seguinte, escolhíamos alguma que tivesse tido destaque e fazíamos a socialização com a turma, isso no início da aula. Em outras ocasiões, no entanto, ressaltamos algumas produções, na intenção de incentivá-los a produzir mais textos escritos.

A partir das imagens notamos o empenho dos educandos na escrita, já que normalmente sentimos uma dificuldade destes quanto a esta tarefa. Contudo, percebemos que uma aluna expressou o seu pensamento escrevendo pelo menos uma lauda. Os demais alunos também participaram sem fazer reclamação, sendo que alguns inclusive se divertiam e nos convidavam a compartilhar cada parágrafo escrito. Isso torna clara a importância da interdisciplinaridade, pois além dos conteúdos específicos das ciências naturais, o tema permite ainda ser trabalho nas demais disciplinas.

Quadro 03. Eixo temático: Medicamentos farmacêuticos/ substâncias produzidas pelas plantas.

\begin{tabular}{|c|c|c|c|}
\hline EIXO TEMÁTICO & QUÍMICA & FÍSICA & BIOLOGIA \\
\hline $\begin{array}{l}\text { Medicamentos } \\
\text { farmacêuticos/ } \\
\text { substâncias produzidas } \\
\text { pelas plantas }\end{array}$ & $\begin{array}{lr}\text { Reações; } & \text { compostos } \\
\text { químicos na bula dos } \\
\text { remédios; } & \text { tabela } \\
\text { periódica; } & \text { óleos } \\
\text { essenciais de plantas, } \\
\text { produção de perfumes e a } \\
\text { separação de substâncias. }\end{array}$ & $\begin{array}{l}\text { (Processos laboratoriais) } \\
\text { Temperatura; calor; }\end{array}$ & $\begin{array}{l}\text { Família botânica das } \\
\text { plantas; os sentidos: } \\
\text { olfato e paladar. }\end{array}$ \\
\hline
\end{tabular}

Fonte: pesquisa de campo, 2015.

A partir do debate sobre a reação dos chás no corpo humano, levantamos uma possível relação entre as reações dos medicamentos encontrados nas farmácias e os remédios produzidos com as plantas naturais. Os alunos trouxeram de casa alguns medicamentos com bula e, por meio destas, apresentamos a tabela periódica, identificando partes destes compostos. A leitura de alguns artigos coletivos permitiunos ainda observar o processo de produção de um medicamento em laboratório e 
realizar uma reflexão coletiva sobre o uso destas substâncias para produção de óleos e dos próprios medicamentos.

A pesquisa da família botânica destas plantas medicinais encontradas na comunidade foi outra atividade que propiciou a interação entre os educandos, pois estes, distribuídos em grupos, fizeram uso da internet para pesquisar sobre as características de cada espécie e a produzir cartazes que seriam expostos na escola.
Essa etapa do projeto, bem como o eixo temático, embora abordados de maneira tímida e restrita, foram eficientes no sentido de trazer informações científicas aos educandos, pois tal como viemos afirmando deste o início desde trabalho, ambos os conhecimentos (científico e tradicional) se completam e devem estar interligados.

\section{Quadro 04. Eixo temático: Como fazer e cuidar de uma muda ou horto medicinal.}

\begin{tabular}{|l|l|l|l|l|}
\hline \multicolumn{1}{|c|}{ EIXO TEMÁTICO } & \multicolumn{1}{|c|}{ QUÍMICA } & \multicolumn{2}{c|}{ FÍSICA } & \multicolumn{1}{c|}{ BIOLOGIA } \\
\hline $\begin{array}{l}\text { Como fazer e cuidar de } \\
\text { uma muda ou horto }\end{array}$ & $\begin{array}{l}\text { Composição da água; } \\
\text { nutrientes que a planta } \\
\text { medicinal (inseticidas } \\
\text { necessita; oxigênio e a } \\
\text { naturais e inseticidas } \\
\text { artificiais) }\end{array}$ & $\begin{array}{l}\text { Relação de energíntese; misturas de } \\
\text { substâncias químicas }\end{array}$ & $\begin{array}{l}\text { conceito de matéria } \\
\text { Fotossíntese; }\end{array}$ & $\begin{array}{l}\text { massa, } \\
\text { orgânica; a importância } \\
\text { da água; os sentidos: } \\
\text { olfato. }\end{array}$ \\
\hline
\end{tabular}

Fonte: pesquisa de campo, 2015.

Para este eixo temático o professor poderá escolher juntamente com os alunos a melhor alternativa de produção, pois além de ser uma atividade prática, requer tempo, espaço e alguns materiais específicos ${ }^{\mathrm{ii}}$.

$\mathrm{Na}$ experiência desenvolvida, optamos juntamente com os educandos por realizar uma coleta de mudas visando o plantio em garrafas PET para serem distribuídas à comunidade no dia da culminância do projeto. Por conta desse planejamento, foi necessária a busca pelo esterco e propício para a plantação dessas mudas. Assim, em conversas com cultivadores de horta da comunidade Nova Conquista, optamos por utilizar o esterco bovino com terra pretaiii, já que estes possuem propriedades químicas que fertilizam a planta, ajudando a mostrar na prática a importância da matéria orgânica para as plantas e seu crescimento.

As turmas foram divididas em duplas para a coleta de garrafas PET pela comunidade. Após as coletas, orientamos os educandos a saírem pela agrovila na qualidade de pesquisadores à procura de mudas para o plantio nestas garrafas. É importante salientar que antes que os educandos saíssem para esta atividade nós 
os instruímos a respeito de como deveriam se comportar nesse tipo de pesquisa escolar, dando a estes a autonomia necessária para a realização da mesma, pois segundo Ninin (2008, p. 21):

$\mathrm{O}$ ato de pesquisar requer um educador que, exercendo seu papel de mediador, abre novos caminhos para seus alunos em direção a investigação, questionando-os e permitindo que questionem, visando a ultrapassar o saber superficial pautado no acúmulo de informações.

A partir desse exercício de pesquisa e coleta, foi possível iniciar o processo de cultivo das mudas.

Observando o entusiasmo dos educandos na aula, já que se trata de aula prática, a mesma provoca o interesse dos educandos na atividade. Em continuidade, esclarecemos a estes a importância de molhar as mudas e conservá-las sempre na presença de muita luz solar, para que estas possam se desenvolver de maneira propícia, ressaltando assim o processo físico, químico e biológico da fotossíntese das plantas.

O professor, no entanto, pode ainda trabalhar a importância crucial da água neste processo, bem como a sua composição química, os estados em que se encontram e a condução dos nutrientes à planta por meio da água.

O cuidado com a sobrevivência da planta é quesito indispensável, tendo em vista novamente a relação intrínseca entre o processo natural e o químico. Partindo desse pressuposto, pode-se ainda abordar um novo eixo temático ou dentro deste mesmo tópico os inseticidas naturais e artificiais, permitindo a continuidade dos conteúdos já trabalhados, como por exemplo, o processo químico de misturas dos compostos.

Além disso, esse eixo temático ainda nos permitiu realizar a produção de outros materiais $^{\text {iv }}$, bem como uma exposição de mudas no espaço escolar, interagindo com outros educandos. Nesta situação, denominamos o projeto como: Exposição de mudas (capim santo, babosa, noni, cidreira, quebra-pedra, malva do reino, romã, gengibre, mastruz) e maquete de horto medicinal.

Esta exposição de mudas e da maquete representou de forma concreta a participação dos educandos no projeto, pois foi permitido mostrar na prática o que foi ensinado nas aulas, tendo os alunos como protagonistas nesse processo produtivo. Também foi permitido aos educandos que ministrassem palestras com o intuito de esclarecer aos demais alunos e colegas à importância da matéria orgânica para o crescimento das plantas, bem como sobre o processo de produção de mudas ou de um horto medicinal. 
Além desta exposição, apresentamos ainda um vídeo produzido pelos educandos, cartazes contendo as informações botânicas das plantas, mural com os textos produzidos pelos alunos, apresentação de um livro em quadrinho produzido pela turma e a degustação de alguns chás utilizados como aperitivo (chá de cidreira, capim santo, hortelã, gengibre). Notamos a interação entre alunos e comunidade.

$\mathrm{O}$ evento também contou com a presença de alunos de outros turnos da escola e da comunidade (crianças, jovens e adultos). Os participantes ganharam mudas das plantas medicinais apresentadas e participaram da degustação de chás.

O eixo temático "Plantas Medicinais" possibilitou, dessa forma, a evolução teórica do pensamento, mas, sobretudo, a interação prática entre escola, educandos e a agrovila. No entanto, para os professores que se propuserem a realizar esta temática, as possibilidades de desenvolvimento das atividades são extremamente amplas e não se restringem às propostas aqui descritas. Cabe a este analisar em conjunto com as turmas a serem trabalhadas as melhores alternativas e conteúdos, pois apesar da simplicidade prática envolvida, por exemplo, um chá, lambedor ou mesmo em uma garrafada, diversos mecanismos físico-químicos complexos estão presentes nos processos de extração, tais como difusão, osmose, pressão de vapor, cinética de reação, dentre outros (Silva, Aguiar \& Medeiros, 2000, p. 20) que podem ser aproveitados em sala de aula como processo metodológico de ensino/aprendizagem na disciplina de Ciências.

\section{As plantas medicinais e o rol de conteúdos relacionados às Ciências da Natureza}

A intensa relação entre plantas medicinais e a realidade encontrada na Agrovila Nova Conquista, em especial entre os alunos da Escola Oziel Alves, incube a escola a buscar uma estratégia de inserção do tema nas disciplinas ministradas, especificamente no ensino de Ciências, haja vista a proximidade entre os conteúdos propostos no currículo do Ensino Fundamental e Ensino Médio. Podemos, assim, trabalhá-los por meio do planejamento a partir de eixo temático, realizando um trabalho interdisciplinar.

É possível subdividir, por exemplo, os conteúdos de cada disciplina específica, como a Biologia, trabalhando termos restritos a esse campo e dando abertura ao tema "Plantas medicinais".

Um foco inicial para uma aula de Biologia sobre o tema poderia partir do levantamento dos conhecimentos prévios dos educandos a respeito da ecologia e 
taxonomia das plantas, como por exemplo, aspectos relacionados às características como: Dá fruto? Tem semente? Então como são classificadas? Além disso, ressaltar o eixo solo-planta-atmosfera, mencionando o processo de fotossíntese da planta, xilema e floema, dentre outros aspectos relevantes.

... os processos extrativos de plantas medicinais baseiam-se em diversos mecanismos físico-químicos tais como, difusão, diluição, fatores cinéticos de reação (temperatura, tempo de aquecimento, superfície de contato, natureza do reagente), pressão de vapor, pressão osmótica etc. ... outro enfoque recai sobre o estudo dos vegetais. Tal conteúdo pode ser preenchido pelas plantas medicinais, abordando-se as suas características físicas, partes empregadas para fazer determinado medicamento fitoterápico, indicações terapêuticas, relatos de experiências do uso das ervas medicinais vivenciadas pelos alunos, entre outras estratégias de ensino, com o objetivo de socializar este importante aspecto da cultura popular (Silva, Aguiar \& Medeiros, 2000, p. 22).

O estudo sistemático deste processo extrativo de plantas, bem como a análise de sua estrutura e dos fatores que influenciam e colaboram no seu desenvolvimento fornecem material extremamente significante para o processo de ensino/aprendizagem do educando, que pode colaborar efetivamente em todas as etapas de construção deste conhecimento.

Por meio deste eixo temático é possível trabalhar diferentes áreas do currículo escolar, abrangendo conteúdos específicos das mais distintas séries e disciplinas, conforme mostra o quadro abaixo.

Quadro 05. Rol de conteúdos de ciências em diálogo com a temática de plantas medicinais.

\begin{tabular}{|c|c|c|c|}
\hline EIXO TEMÁTICO & QUÍMICA & FÍSICA & BIOLOGIA \\
\hline Plantas medicinais & $\begin{array}{lr}\text { Reações; } & \text { misturas } \\
\text { homogêneas } & \mathrm{e} \\
\text { heterogêneas; } & \\
\text { soluções. } & \end{array}$ & $\begin{array}{l}\text { (Chás) temperatura, tempo } \\
\text { de aquecimento. }\end{array}$ & $\begin{array}{l}\text { Estrutura da planta; } \\
\text { biodiversidade; tríade } \\
\text { solo-planta-atmosfera. }\end{array}$ \\
\hline $\begin{array}{l}\text { Medicamentos } \\
\text { farmacêuticos/ } \\
\text { substâncias produzidas } \\
\text { pelas plantas }\end{array}$ & $\begin{array}{lr}\text { Reações; } & \text { compostos } \\
\text { químicos na bula dos } \\
\text { remédios; } & \text { tabela } \\
\text { periódica; } & \text { óleos } \\
\text { essenciais de plantas } \\
\text { para a produção de } \\
\text { perfumes e r a } \\
\text { separação } & \\
\text { substâncias. } & \\
\end{array}$ & $\begin{array}{l}\text { (Processos laboratoriais) } \\
\text { Temperatura e calor. }\end{array}$ & $\begin{array}{l}\text { Família botânica das } \\
\text { plantas originais; os } \\
\text { sentidos: olfato e paladar. }\end{array}$ \\
\hline $\begin{array}{l}\text { Como fazer e cuidar de } \\
\text { uma muda } \text { ou horto } \\
\text { medicinal } \\
\begin{array}{l}\text { (inseticidas } \\
\text { naturais e } \\
\text { artificiais) }\end{array}\end{array}$ & $\begin{array}{l}\text { Composição da água; } \\
\text { nutrientes que a planta } \\
\text { necessita; oxigênio e a } \\
\text { fotossíntese; misturas. }\end{array}$ & $\begin{array}{l}\text { Relação de energia; conceito } \\
\text { de massa, matéria. }\end{array}$ & $\begin{array}{l}\text { Fotossíntese; matéria } \\
\text { orgânica; a importância } \\
\text { da água; os sentidos: } \\
\text { olfato. }\end{array}$ \\
\hline
\end{tabular}

\section{Fonte: Pesquisa de campo, 2015.}


Conforme notamos no quadro, as possibilidades de realização de um trabalho ou projeto a ser feito com esta temática é amplamente relacionado aos conteúdos que discorrem durante o ano letivo e vão de encontro às demandas encontradas no decorrer da pesquisa realizada com os educandos do $6^{\circ}$ ao $9^{\circ}$ ano do Ensino Fundamental da escola em questão, validando aspectos direcionados propriamente do tema proposto e construindo um currículo diferenciado com base nos interesses locais.

Diante do desafio de ligar os educandos e o conhecimento tradicional sobre as plantas medicinais, e fazer isso de maneira a superar o método de ensino tradicional; a partir de uma metodologia diferenciada, de maneira interdisciplinar e prática, desenvolvemos um projeto nas turmas do Ensino Fundamental, tendo como principal protagonista a tríade escola-educando-comunidade.

As aulas foram organizadas de forma que interligasse o método teórico e prático nas disciplinas de Química, Física e Biologia (quer no Ensino Fundamental ou Ensino Médio).

Dessa forma, organizamos uma sequência de aulas que possibilita a apreensão teórica, prática e participativa em todos os momentos, permitindo a interação entre escola e comunidade em todas as suas etapas.

Por meio da proposta curricular discorrida, bem como da experiência realizada com as turmas do $6^{\circ}$ ao $9^{\circ}$ ano do Ensino Fundamental, entendemos que o processo metodológico possui maior eficiência se discutido por eixos temáticos e através de práticas interdisciplinares. E que dessa forma, conceitos físicos, químicos e biológicos aparentemente de difícil visualização tornam-se comuns se vivenciados na prática.

Assim, primando pela afirmação de princípios éticos e de indissociabilidade teórico-prática, pensamos no processo avaliativo como mais um momento de aprendizagem. Desta maneira, a avaliação é compreendida no curso de Educação do Campo como um processo diagnóstico, investigativo, formativo, sistemático, contínuo, participativo e que deve possibilitar aos sujeitos participantes o redimensionamento das ações desenvolvidas, apontando a necessidade de avançar ou retomar determinados objetivos propostos, constituindo-se dessa forma em um exercício permanente de diálogo sobre o processo ensino/aprendizagem.

Assim, para representar as demandas dos sujeitos coletivos que vivem no campo, atividades didáticas desse tipo garantem: 
a) Uma formação contextualizada;

b) Indivíduo visto como sujeito do conhecimento;

c) Indissociabilidade entre teoria e prática;

d) A pesquisa como princípio educativo;

e) A realidade das comunidades rurais e assentamentos como objeto de estudo e fonte de conhecimento;

f) O planejamento de ações formativas por área do conhecimento;

g) $\mathrm{O}$ trabalho pedagógico como objeto de transformação da realidade.

Por fim, acreditamos que dessa maneira os conteúdos de ciências aliados a Educação do Campo possam contribuir para manutenção de assentamentos e comunidades rurais, locais muitas vezes marcados pelo esquecimento e invisibilidade, mas que por outro lado representa um território de existência coletiva, pela reprodução socioeconômica e pela relação sociedade-natureza.

\section{Considerações finais}

Ao longo do tempo a concepção de conhecimento se alterou muito. Se a princípio cada grupo ou comunidade ia descobrindo suas próprias crenças e valores por meio de suas experiências vivenciadas, a partir da evolução do pensamento científico a ciência constituise como principal fonte de verdade e/ou principal meio de se chegar a ela. Este processo pode ser observado de maneira muito intensa nos aspectos aqui mencionados sobre as plantas medicinais no decorrer deste trabalho.

Entendemos assim, que em detrimento do conhecimento empírico tem sido desperdiçado um conhecimento coletivo que vigorou ao longo dos séculos, sendo construído e conduzido de geração em geração, passando por observações e experimentações práticas, indutivas, a partir das quais o conhecimento científico se constrói e propõe suas investigações.

Tendo em vista a gravidade que é o acúmulo dessas substâncias químicas no organismo e os efeitos colaterais advindos de sua ingestão, o objetivo deste trabalho é reafirmar a medicina popular como a melhor alternativa no auxílio de tratamentos e prevenção de diversos males, pois, a concentração destes componentes está em menor quantidade nas plantas e isso reduz o risco de problemas indesejáveis.

Nessa perspectiva, é singular a construção do conhecimento tradicional como uma alternativa para os mais diferentes grupos que têm se constituído a partir de suas experiências de vida, 
organizando-se de maneira a garantir a permanência de seus conhecimentos.

A proposição de novas práticas de ensino-aprendizagem que partem da compreensão da realidade dos alunos e trazem para o ensino de Ciências conteúdos relacionados ao cotidiano dos envolvidos no processo de ensinoaprendizagem, permitirão uma melhor interação entre professores e alunos proporcionada por meio de uma perspectiva construtivista e dialógica.

A proposta possibilitou avançarmos na discussão existente em torno da interdisciplinaridade no ensino de Ciências no curso de Licenciatura em Educação do Campo, permitindo novas interpretações e maior sensibilização ao tratar desta temática que muitas vezes se materializa apenas no âmbito da comunicação entre professores das diferentes áreas do conhecimento, mas que de fato não interrelacionam os saberes dos alunos com os saberes científicos envoltos em torno dos conteúdos programáticos. Assim, para além de escrever sobre esse tema, nos desafiamos a promover mudanças/rupturas na prática docente concatenada neste curso, uma vez que passamos a ouvir/dar voz aos alunos, contribuindo dessa forma para o processo de mudanças das práticas pedagógicas.
Acreditamos que este projeto representa a vontade de protagonização dos sujeitos do campo que ao longo da história foram invisibilizados, mesmo que a contragosto por uma matriz curricular que não englobam suas particularidades e necessidades.

A agrovila Nova Conquista-MA, comunidade pesquisada é, dessa forma, privilegiada pela diversidade em torno das 42 espécies medicinais encontradas em seu espaço e, consequentemente, um inestimável recurso natural à disposição dos assentados. Reconhecer e cultivar essas espécies são responsabilidades de todos os sujeitos envolvidos nesse processo de retomada aos princípios ecológicos, inclusive da escola, que se constitui nesse espaço como um dos principais instrumentos de propagação do conhecimento.

Reafirmamos que os apontamentos apresentados neste artigo não pretendem ser conclusivos, mas visam à reflexão sobre o papel da escola na permanência do conhecimento tradicional, propondo práticas pedagógicas alternativas tendo como temática as plantas medicinais.

\section{Referências}

Arroyo, M. (2008). Ofício de Mestre, Imagem e auto-imagem. Petrópolis: Vozes. 
Barbosa, W. (2009). Fitoterapia popular e ciência farmacêutica. Belém: NUMA/UFPA.

Camargo, M. (2014). As plantas medicinais $e$ o sagrado: a etnofarmacobotânica em uma revisão historiográfica da medicina popular no Brasil. São Paulo: Ícone.

Diegues, A. (2009). Os saberes tradicionais e a biodiversidade no Brasil. NUPAUB: Núcleo de Pesquisas sobre Populações Humanas e Áreas Úmidas Brasileiras/Universidade de São Paulo: São Paulo.

Fernandes, T. (2004). Plantas medicinais: memória da ciência no Brasil. Rio de Janeiro: Editora Fiocruz.

Freire, P. (1996). Pedagogia da autonomia: saberes necessários a pratica educativa. São Paulo: Paz e Terra.

Ninin, M. (2008). Pesquisa na escola: que espaço é esse? O do conteúdo ou o do pensamento crítico? Educação em Revista, (48), 17-35.

Silva, P., Aguiar, L., \& Medeiros, C. (2000). O Papel do Professor na Produção de Medicamentos Fitoterápicos. Revista Química Nova na Escola, (11), 20-22.

\footnotetext{
${ }^{\text {i }}$ A concepção de Educação do Campo contrapõe-se à visão tradicional de educação rural, assim o campo é concebido enquanto espaço social com vida, identidade e cultura própria e práticas compartilhadas, socializadas por aqueles que ali vivem. Sendo assim, a educação do campo deve refletir a vida, os interesses e as necessidades de desenvolvimento desses indivíduos e não reproduzir os valores do desenvolvimento urbano (Arroyo, 2008).

ii Substrato (areia, argila, serragem, palha de arroz, esterco bovino), garrafas pet, tesoura, sementes, substratos vegetais (galhos, raízes).
}

iii Dito popular: Pó encontrado em caeiras e carvoeiras, por isso conhecido como terra preta.

${ }^{\text {iv }}$ Cartazes apresentado a comunidade escolar com informações sobre as famílias botânicas das plantas e cartilha com informações sobre as plantas medicinais encontradas na comunidade Nova Conquista.

Recebido em: 28/08/2016 Aprovado em: 21/09/2016 Publicado em: 19/04/2017

Como citar este artigo / How to cite this article / Como citar este artículo:

APA:

Moreno, G. S., \& Silva, G. (2017). Conhecimentos tradicionais em torno das plantas medicinais e currículo do ensino de ciências. Rev. Bras. Educ. Camp., 2(1), 144-162. DOI: http://dx.doi.org/10.20873/uft.25254863.2017v2n1p144

ABNT:

MORENO, G. S.; SILVA, G. Conhecimentos tradicionais em torno das plantas medicinais e currículo do ensino de ciências. Rev. Bras. Educ. Camp., Tocantinópolis, v. 2, n. 1, p. 144-162, 2017. DOI: $\quad$ http://dx.doi.org/10.20873/uft.25254863.2017v2n1p144 
Moreno, G. S., \& Silva, G. (2017). Conhecimentos tradicionais em torno de plantas medicinais... 